\title{
FATORES QUE AFETAM A EFICIÊNCIA DE INSETICIDAS SOBRE Spodoptera frugiperda Smith EM MILHO ${ }^{1}$
}

\author{
FACTORS LIMITING THE EFFICIENCY OF INSECTICIDES \\ TO CONTROL Spodoptera frugiperda Smith IN MAIZE
}

\author{
Mauro Tadeu Braga da Silva ${ }^{2}$
}

RESUMO

A lagarta-do-cartucho (Spodoptera frugiperda) é uma praga importante do milho (Zea mays L.), sendo muitas vezes controlada com inseticidas. Nos municípios de Cruz Alta, Fortaleza dos Valos e Pejuçara - RS, há relatos de ineficiência de inseticidas. Neste sentido, foram conduzidos três experimentos a campo envolvendo, respectivamente, época, modo e volume de aplicação de inseticidas. As avaliações, baseadas no número de lagartas vivas e mortas por planta, foram realizadas aos quatro e oito dias após a aplicação dos inseticidas. A eficiência dos inseticidas variou em função da época, modo de aplicação e do volume de calda aplicado, sendo menor nas aplicações tardias (danos severos), em área total e com menor volume de calda (150l/ha). Entretanto, maior eficiência foi observada nas aplicações logo que surgiam os primeiros sintomas de ataque, apenas sobre a fileira das plantas, dirigindo-se o jato para o interior do cartucho e com maior volume de calda (300l/ha). O inseticida lufenurom (12,5g i.a./ha), usado nos três experimentos, propiciou maior nível de controle.

Palavras-chave: Insecta, controle de pragas, inseticidas, métodos de aplicação.

\section{SUMMARY}

The fall armyworm (Spodoptera frugiperda) is an important insect pest of maize, being frequently controlled through the use of insecticides. In the counties of Cruz Alta, Fortaleza dos Valos and Pejuçara, Rio Grande do Sul State, there have been reports of low insecticide efficiency. Three field experiments were conducted including different application methods, timing and volume of insecticides. The evaluation was based on number of live and dead larvae per plant at four and eight days after treatment. The results showed that the efficiency of insecticides varied with the application method and timing, as well as with the volume of suspension applied. Lower insecticide efficacy was observed for late application (when damage was

\begin{abstract}
severe), for the method of application on total surface area and using smaller volume of suspension (150l/ha). Increased insecticide control was observed when they were applied at the beggining of insect attack and directing the spray toward the inside of the plant whorl and with higher suspension volume (300l/ha). The insecticide lufenuron (12.5g a. i./ha), in three field experiments, provided high insect control.
\end{abstract}

Key-words: Insecta, pest control, insecticides, application methods.

\section{INTRODUÇÃO}

A lagarta-do-cartucho, Spodoptera frugiperda Smith, 1797 (Lepidoptera: Noctuidae), é uma das mais importantes pragas da cultura do milho no Brasil. CARVALHO (1970) registrou uma perda de rendimento de grãos de 15 a $34 \%$ e que o dano prejudicou o desenvolvimento das plantas e reduziu a massa das espigas produzidas, quando as plantas de milho apresentavam o cartucho destruído pelo ataque da praga. CRUZ \& TURPIN (1982) evidenciaram redução no rendimento de grãos do milho de aproximadamente $19 \%$, quando infestações artificiais foram realizadas em plantas no estádio de 8 a 10 folhas, aproximadamente de 45 dias após a semeadura

Após a oviposição, a lagarta eclode num período de três a cinco dias, iniciando sua alimentação em folhas abertas, raspando-as sem perfurá-las. A partir do $4^{0}$ ínstar, ataca preferencialmente o cartucho da planta, consumindo grande parte da área

\footnotetext{
${ }^{1}$ Trabalho apresentado no $17^{\circ}$ Congresso Brasileiro de Entomologia, Rio de Janeiro, RJ, de 9 a 14.08.98.

${ }^{2}$ Engenheiro Agrônomo, MSc., FUNDACEP FECOTRIGO, CP 10, 98100-970, Cruz Alta, RS. E-mail: fundacep@azcomnet.com.br. Autor para correspondência.
} 
foliar antes das folhas emergirem do cartucho e, em completo desenvolvimento, ataca todas as folhas centrais, chegando a destruir completamente o cartucho. Devido ao canibalismo, é comum encontrar-se apenas uma lagarta desenvolvida por cartucho, podendo-se encontrar lagartas em ínstares diferentes num mesmo cartucho, separadas pelas lâminas das folhas. Em razão do número elevado de plantas hospedeiras, como milho, arroz, sorgo, soja, feijão, capins (papuã, milhã, capim-elefante, grama-seda), cana-de-açúcar, trigo, aveia, algodão, alface, batata, amendoim (SILVA et $\boldsymbol{a l}$., 1968), dentre outras, somando-se o cultivo de milho na safrinha, as infestações de $\boldsymbol{S}$. frugiperda vêm aumentando progressivamente e, conseqüentemente, o número de aplicações de inseticidas para seu controle.

Alguns casos de ineficiência de inseticidas foram observados em Cruz Alta, Fortaleza dos Valos e Pejuçara - RS, especialmente nos plantios de novembro a janeiro, que coincidem com períodos de estiagem. Esses problemas demandam pesquisas sobre as possíveis causas de insucesso, a fim de equacioná-los, para melhorar o controle da praga. Entre os fatores que podem influenciar negativamente a eficiência de inseticidas no controle de $\boldsymbol{S}$. frugiperda, em milho, está o combate tardio e métodos inadequados de aplicação (ALMEIDA $\boldsymbol{e t} \boldsymbol{a l}$., 1964 e 1966; CRUZ \& SANTOS, 1984).

O objetivo deste trabalho foi verificar fatores que limitam a eficiência de inseticidas em populações naturais da lagarta-do-cartucho e comparar época, modo e volume de calda de aplicação, com diversos inseticidas sobre esta praga.

\section{MATERIAL E MÉTODOS}

Três experimentos foram realizados a campo em área experimental da Fundacep Fecotrigo, em Cruz Alta, RS. O delineamento experimental foi o de blocos ao acaso com parcelas subdividas em cinco repetições. As áreas experimentais foram conduzidos segundo as práticas recomendadas para a cultura do milho na região. A semeadura foi feita com uma semeadora-adubadora "PAR 2800" de quatro linhas, espaçadas de $0,9 \mathrm{~m}$, numa densidade de seis sementes por metro, em parcelas de quatro fileiras e sete metros de comprimento. Foi considerada como parcela útil as duas fileiras centrais, desprezando-se meio metro em cada extremidade. Os inseticidas usados nos experimentos foram clorpirifós a 288g.i.a./ha (Lorsban $480 \mathrm{BR}, 600 \mathrm{ml} / \mathrm{ha}$ ), deltametrina a 3,75g.i.a./ha (Decis 25 CE, 150ml/ha), diflubenzurom a 25g.i.a./ha (Dimilin 250 PM, 100g/ha), lambdacialotrina a 7,5g.i.a./ha (Karate $50 \mathrm{CE}, 150 \mathrm{ml} / \mathrm{ha}$ ), lufenurom a $12,5 \mathrm{~g} .1 . \mathrm{a} . / \mathrm{ha}$
(Match $50 \mathrm{CE}, 250 \mathrm{ml} / \mathrm{ha}$ ), metomil a 129g.i.a./ha (Lannate $215 \mathrm{BR}, 600 \mathrm{ml} / \mathrm{ha}$ ), teflubenzurom a 15g.i.a./ha (Nomolt $150 \mathrm{SC}, 100 \mathrm{ml} / \mathrm{ha}$ ) e triflumurom a 25g.i.a./ha (Alsystim $250 \mathrm{PM}, 100 \mathrm{~g} / \mathrm{ha}$ ). Avaliou-se o número de lagartas vivas e mortas por planta, com mais de $0,5 \mathrm{~cm}$ de comprimento, aos quatro e oito dias após a aplicação. Para efeito de análise estatística, os dados do número de lagartas foi transformado em $\sqrt{\mathrm{x}+0,5}$ e as comparações entre médias foram feitas através do teste de Duncan em nível de $5 \%$ de probabilidade.

Experimento 1 - Época de aplicação. Os tratamentos foram representados por duas épocas de aplicação: início de ataque (100\% lagartas pequenas, com menos de $1,5 \mathrm{~cm}$ de comprimento e sintomas de folhas raspadas) e dano severo (30\% lagartas pequenas e $70 \%$ lagartas grandes, com mais de $1,5 \mathrm{~cm}$ de comprimento e sintomas de folhas raspadas e cartuchos destruídos). Os subtratamentos foram compreendidos pelas testemunhas sem controle (água) e pelos inseticidas diflubenzurom, lufenurom, metomil e triflumurom. Foi usado o cultivar de milho híbrido simples modificado Pionner 3069, de ciclo superprecoce.

$\mathrm{Na}$ primeira época, os inseticidas foram aplicados em 03 de março de 1996, aos 35 dias após a semeadura do milho safrinha, com as plantas apresentando cerca de $45 \mathrm{~cm}$ de altura e uma infestação média de $50 \%$, representando o tratamento início de ataque. Na segunda época, os inseticidas foram aplicados em 07 de março de 1996, com as plantas apresentando cerca de $55 \mathrm{~cm}$ de altura e $75 \%$ de infestação média, representando o tratamento dano severo. Para aplicação, usou-se um pulverizador costal, pressurizado com ar comprimido, com bico leque 80 04 , na pressão de $1,4 \mathrm{~kg} / \mathrm{cm}^{2}$ e num volume de calda equivalente a $300 l / \mathrm{ha}$. A aplicação foi feita sobre a fileira, com o bico posicionado a cerca de $10 \mathrm{~cm}$ de altura em relação ao cartucho das plantas, dirigindose o jato para o interior do cartucho.

Experimento 2 - Modo de aplicação. Os tratamentos foram representados por duas formas de aplicação: sobre a fileira (1 bico numa altura de aproximadamente $10 \mathrm{~cm}$ em relação ao cartucho das plantas, dirigindo-se o jato para o interior do cartucho) e área total (barra com 5 bicos espaçados de $50 \mathrm{~cm}$, numa altura de $50 \mathrm{~cm}$ em relação ao cartucho). Os subtratamentos foram constituídos pelas testemunhas sem controle (água) e pelos inseticidas lambdacialotrina, lufenurom e teflubenzurom. Foi usado o cultivar de milho híbrido simples Cargill 901, de ciclo superprecoce.

Os inseticidas foram aplicados, em $06 \mathrm{de}$ dezembro de 1996, aos 25 dias após a semeadura, com as plantas apresentando cerca de $30 \mathrm{~cm}$ de altura 
e uma infestação inicial média de $30 \%$, composta de lagartas pequenas. Usou-se um pulverizador costal pressurizado a ar comprimido, com bico leque 8004 na pressão de $1,4 \mathrm{~kg} / \mathrm{cm}^{2}$ e num volume de calda equivalente a $300 / /$ ha.

Experimento 3 - Volume de calda. Os tratamentos foram representados pelos volumes de calda de 150 e 300l/ha, enquanto que os subtratamentos constituíram-se das testemunhas sem controle (água) e os inseticidas clorpirifós, deltametrina e lufenurom. Foi usado o cultivar de milho híbrido Pionner 3069. Os inseticidas foram aplicados, em 03 de março de 1996, aos 35 dias após a semeadura do milho safrinha, com pulverizador costal pressurizado a ar comprimido, com bico leque 80 04, trabalhando numa pressão de $1,4 \mathrm{~kg} / \mathrm{cm}^{2}$, com as plantas apresentando cerca de $45 \mathrm{~cm}$ de altura e uma infestação inicial média de $70 \%$, composta de lagartas pequenas. $\mathrm{O}$ volume de calda menor foi obtido dobrando-se a velocidade de deslocamento do operador. A aplicação foi feita sobre a fileira, com o bico posicionado numa altura de aproximadamente $10 \mathrm{~cm}$ em relação ao cartucho da plantas, dirigindo-se o jato para o interior do cartucho.

\section{RESULTADOS E DISCUSÃO}

Experimento 1 - Época de aplicação. Houve interação significativa entre época de aplicação e os inseticidas para o número de lagartas (tabela 1). O número de lagartas nos subtratamentos com inseticidas foi diferente entre as duas épocas de aplicação. A aplicação feita no início do ataque apresentou menor número de lagartas em comparação com a aplicação feita com dano severo, para todos os inseticidas. Esses resultados demonstram a maior e menor suscetibilidade de lagartas pequenas e grandes, respectivamente, aos inseticidas. Estes resultados estão de acordo com ALMEIDA et al. (1964), que concluíram que o combate tardio figura como um dos principais fatores de insucesso no controle de $S$. frugiperda. Apesar da separação dos inseticidas em dois grupos, quando da aplicação no início do ataque, representados pelo lufenurom (melhor) e triflumurom (pior) e acompanhados pelo diflubenzurom e metomil, que se eqüivaleram a ambos, observou-se que o controle mais baixo foi de $84 \%$, considerado um nível aceitável. À aplicação feita com dano severo, muito embora houvesse também separação dos inseticidas em dois grupos, lufenurom e diflubenzurom melhores que triflumurom e metomil, notou-se que o controle mais alto foi de $74 \%$, considerado um nível não aceitável. Em ambas modalidades de aplicação, os inseticidas foram significativamente superiores às testemunhas $(\mathrm{P} \leq 0,05)$, com menor número de lagartas.

Experimento 2 - Modo de aplicação. Para o número de lagartas (tabela 2), houve interação significante entre o modo de aplicação e os inseticidas. Observaram-se diferenças para o número de lagartas com a aplicação de inseticida em área total, com maior número, e sobre a fileira, com menor número, independente do inseticida usado, excetuando-se as testemunhas. $\mathrm{O}$ aumento de eficiência no controle de lagartas entre subparcelas com aplicação em área total, e sobre a fileira, passou de 32 para $97 \%$ (lambdacialotrina), 58 para $94 \%$ (lufenurom) e 45 para $72 \%$ (teflubenzurom). A menor eficiência na aplicação em área total pode ser creditada à perda de cerca de $55 \%$ do volume de calda e, conseqüentemente, da dosagem dos inseticidas, os quais foram aplicados também sobre o solo ou restos

Tabela 1 - Número médio de lagartas ${ }^{1}$ e porcentagem de controle ${ }^{2}$ de Spodoptera frugiperda em duas épocas de aplicação e diversos inseticidas.

\begin{tabular}{|c|c|c|c|c|c|}
\hline \multirow{2}{*}{$\begin{array}{c}\text { Época } \\
\text { De } \\
\text { Aplicação }\end{array}$} & \multicolumn{5}{|c|}{ Inseticida } \\
\hline & Lufenurom & Diflubenzurom & Triflumurom & Metomil & $\begin{array}{l}\text { Testemunha } \\
\text { (Água) }\end{array}$ \\
\hline Dano Severo & $\begin{array}{l}6,2 \text { a D } \\
(74 \%)\end{array}$ & $\begin{array}{c}8,0 \text { a CD } \\
(67 \%)\end{array}$ & $\begin{array}{l}9,8 \text { a BC } \\
(59 \%)\end{array}$ & $\begin{array}{l}11,8 \text { a B } \\
(51 \%)\end{array}$ & 24,0 a $\mathrm{A}$ \\
\hline Início Ataque & $\begin{array}{l}1,0 \mathrm{~b} \mathrm{C} \\
(95 \%)\end{array}$ & $\begin{array}{l}2,0 \mathrm{~b} \mathrm{BC} \\
(90 \%)\end{array}$ & $\begin{array}{l}3,2 \mathrm{~b} \mathrm{~B} \\
(84 \%)\end{array}$ & $\begin{array}{l}2,4 \mathrm{~b} \mathrm{BC} \\
\quad(88 \%)\end{array}$ & 19,6 b A \\
\hline \multirow{3}{*}{\multicolumn{2}{|c|}{$\begin{array}{c}\text { CV \% Época de Aplicação } \\
\text { CV \% Inseticida }\end{array}$}} & 10,85 & & & \\
\hline & & 14,02 & & & \\
\hline & & F & Probabilidade & & \\
\hline \multicolumn{2}{|c|}{ Época de Aplicação } & 210,62 & 0,000533 & & \\
\hline \multirow{2}{*}{\multicolumn{2}{|c|}{$\begin{array}{c}\text { Inseticida } \\
\text { Época de Aplicacão x }\end{array}$}} & 79,82 & 0,000000 & & \\
\hline & & & & & \\
\hline \multicolumn{2}{|c|}{ Época de Aplicação x } & 3,81 & 0,012190 & & \\
\hline
\end{tabular}

${ }^{1}$ Médias nas colunas seguidas da mesma letra minúscula e nas linhas seguidas da mesma letra maiúscula não diferem entre si pelo teste de Duncan $(\mathrm{P} \leq 0,05)$.

${ }^{2}$ Entre parênteses, porcentagem de controle calculada pela fórmula de ABBOTT (1925), considerando a testemunha da sua respectiva época de aplicação. 
Tabela 2 - Número médio de lagartas ${ }^{1}$ e porcentagem de controle ${ }^{2}$ de Spodoptera frugiperda em dois modos de aplicação e diversos inseticidas.

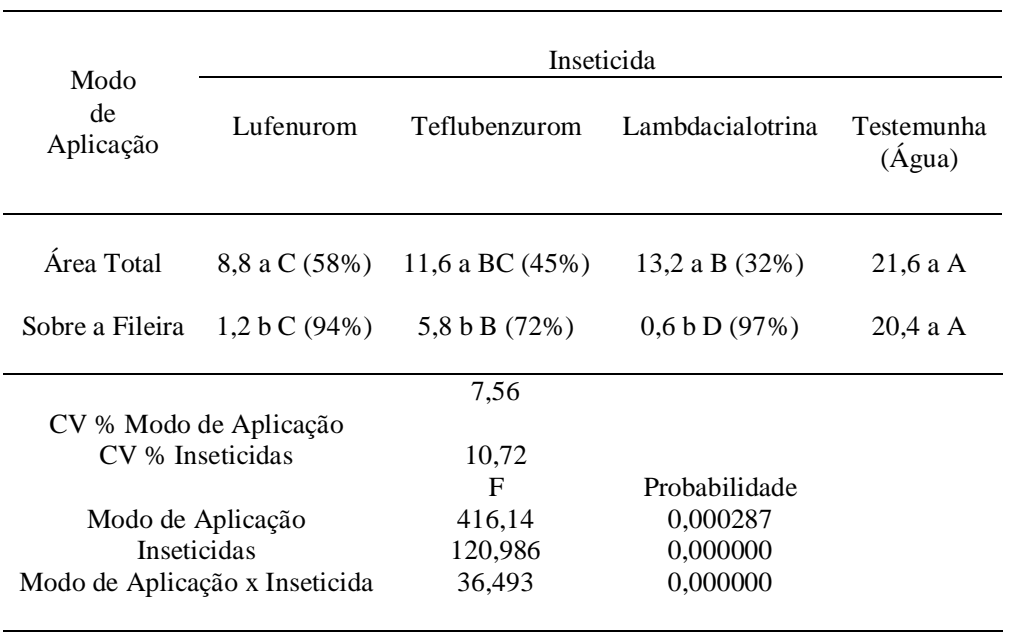

${ }^{1}$ Médias nas colunas seguidas da mesma letra minúscula e nas linhas seguidas da mesma letra maiúscula não diferem entre si pelo teste de Duncan $(\mathrm{P} \leq 0,05)$.

${ }^{2}$ Entre parênteses, porcentagem de controle calculada pela fórmula de ABBOTT (1925), considerando a média das duas testemunhas (21,0 lagartas em 30 plantas).

culturais entre as fileiras de plantas. Assim, menos da metade do volume de calda e da dosagem aplicada teve acesso ao ponto de localização da praga, reduzindo de modo considerável a eficiência dos inseticidas.

Esses resultados concordam com MARTINS \& SAWADA (1995) que demonstraram maior eficiência da aplicação com jato dirigido para o cartucho da planta do que aquela em área total. ALMEIDA et al. (1964 e 1966) atribuíram melhor eficiência de inseticidas no controle de $\boldsymbol{S}$. frugiperda quando aplicados com bicos de jato tipo leque 6502 e 8002 , que depositam o inseticida diretamente no local de ataque da praga. Quando utilizaram bicos de jato cônico, com interior oco, que são usados em aplicações nas copas das plantas, os inseticidas foram ineficientes. Na aplicação feita sobre a fileira, o inseticida lambidacialotrina apresentou maior controle que o lufenurom que, por sua vez, superior ao teflubenzurom e todos superiores à testemunha. A eficiência baixa $(72 \%)$ alcançada por teflubenzurom não é considerado como bom nível de controle. Com relação à aplicação em área total, nota-se que todos os inseticidas apresentaram um baixo nível de controle (32 a 58\%), embora superiores à testemunha $(\mathrm{P} \leq 0,05)$.

Experimento 3 - Volume de calda. Houve interação significativa entre volume de calda e inseticidas $(P \leq 0,05)$, para o número de lagartas (tabela 3 ). O desempenho dos inseticidas foi dependente do volume de calda utilizado, com menor número de lagartas no maior volume de calda. Por outro lado, nas testemunhas não houve diferença no número de lagartas entre os dois volumes de calda. Observou-se alta eficiência dos inseticidas, com controles variando entre 90 e $96 \%$, quando aplicados com 300l/ha. No entanto, houve decréscimo no número de lagartas com o uso de clorpirifós para lufenurom e deste para deltametrina, os quais diferiram da testemunha. Estes inseticidas apresentaram baixa eficiência (32 a 60\%), quando aplicados com volume de calda de $150 /$ ha. Nesse volume, o número de lagartas decresceu na seguinte ordem: testemunha, deltametrina, clorpirifós e lufenurom.

Tabela 3 - Número médio de lagartas $^{1}$ e porcentagem de controle ${ }^{2}$ de Spodoptera frugiperda em dois volumes de calda e diversos inseticidas.

\begin{tabular}{|c|c|c|c|c|}
\hline \multirow{2}{*}{ Volume de Calda } & \multicolumn{4}{|c|}{ Inseticida } \\
\hline & Lufenurom & Deltametrina & Clorpirifós & $\begin{array}{c}\text { Testemunha } \\
\text { (Água) }\end{array}$ \\
\hline $150 \mathrm{l} / \mathrm{ha}$ & 10,0 a D $(60 \%)$ & 17,2 a B $(32 \%)$ & 13,2 a C $(47 \%)$ & 24,8 a $\mathrm{A}$ \\
\hline $300 \mathrm{l} / \mathrm{ha}$ & 1,8 b BC $(93 \%)$ & 1,0 b C $(96 \%)$ & 2,6 b B $(90 \%)$ & 25,6 a $A$ \\
\hline \multirow{3}{*}{\multicolumn{2}{|c|}{$\begin{array}{c}\text { CV \% Volume de Calda } \\
\text { CV \% Inseticidas }\end{array}$}} & 5,02 & & \\
\hline & & 8,93 & & \\
\hline & & $\mathrm{F}$ & Probabilidade & \\
\hline \multicolumn{2}{|c|}{ Volume de Calda } & 1048,44 & 0,000152 & \\
\hline \multicolumn{2}{|c|}{ Inseticidas } & 183,810 & 0,000000 & \\
\hline \multicolumn{2}{|c|}{ Volume de Calda x Inseticida } & 51,046 & 0,000000 & \\
\hline
\end{tabular}

${ }^{1}$ Médias nas colunas seguidas da mesma letra minúscula e nas linhas seguidas da mesma letra maiúscula não diferem entre si pelo teste de Duncan $(\mathrm{P} \leq 0,05)$.

${ }^{2}$ Entre parênteses, porcentagem de controle calculada pela fórmula de ABBOTT (1925), considerando a média das duas testemunhas (25,2 lagartas em 30 plantas). 
São escassos e discordantes os dados de literatura referentes à utilização de diferentes volumes de calda para o controle de $\boldsymbol{S}$. frugiperda em milho. Os resultados satisfatórios no controle desta lagarta, apresentados pelos inseticidas quando aplicados com maior volume de calda no presente trabalho, confirmam os resultados obtidos por CRUZ et al. (1996). Por outro lado, CRUZ \& SANTOS (1984) demonstraram eficiência de inseticidas com uso de bicos de ângulo 65 e 80 graus trabalhando com volume de calda de 135l/ha. Embora neste último trabalho citado não houvesse comparação entre volumes de calda, os resultados alcançados foram melhores que os obtidos com a vazão de $150 l /$ ha no presente trabalho.

A manipulação, em conjunto, da época (início de ataque), do modo (sobre a fileira, com jato dirigido para o interior do cartucho) e do volume de calda (maior) de aplicação de inseticidas pode representar boa prática a ser utilizada visando a melhorar o controle de $\boldsymbol{S}$. frugiperda, na cultura do milho. Os dados obtidos neste estudo e as observações de lavouras cultivadas com milho, na região de Cruz Alta (incluindo os municípios de Fortaleza dos Valos e Pejuçara), explicam os insucessos das aplicações de inseticidas realizadas pelos agricultores, em anos de infestação do inseto. Geralmente, os agricultores realizam o combate tardio (infestações altas e presença de lagartas grandes) à praga e utilizam métodos inadequados de aplicação de inseticidas, como pulverizações em área total com pequenos volumes de calda (70 a 100l/ha), as quais são freqüentemente utilizadas nas aplicações de herbicidas.

\section{CONCLUSÃO}

A eficiência dos inseticidas, no controle de $S$. frugiperda, em milho, varia em função da época, do modo de aplicação e do volume de calda aplicado. A eficiência é menor nas aplicações tardias, em área total e com menor volume de calda e aumenta nas aplicações realizadas logo que surjam os primeiros sintomas de ataque, apenas sobre a fileira, dirigindo-se o jato para o interior do cartucho das plantas e com maior volume de calda.

\section{REFERÊNCIAS BIBLIOGRÁFICAS}

ABBOTT, W.S. A method of computing the effectiveness of an insecticide. Journal of Economic Entomology, College Park, v. 18 , p. $265-267,1925$.

ALMEIDA, P.R., CAVAlCANTE, R.D., BITRAN, E.A. Ensaio de campo com inseticidas granulados no combate à lagarta do cartucho - Laphygma frugiperda (Smith \& Abbot, 1797). O Biológico, São Paulo, v. 32, n. 3, p. 52-54, 1966.

ALMEIDA, P.R., CAVALCANTE, R.D., SORDI, G. de. Ensaio com inseticidas modernos no combate à lagarta do cartucho Laphygma frugiperda (Smith \& Abbot, 1797) e técnica de aplicação. O Biológico, São Paulo, v. 30, n. 5, p. 111-114, 1964.

CARVALHO, R.P.L. Danos, flutuação da população, controle e comportamento de Spodoptera frugiperda (J.E.Smith 1797) e susceptibilidade de diferentes genótipos de milho em condições de campo. Piracicaba - SP. 170 p. (Tese de Doutorado) - Escola Superior de Agricultura "Luiz de Queiroz"/USP, 1970.

CRUZ, C., SANTOS, J.P. dos. Diferentes bicos do tipo leque no controle da lagarta-do-cartucho em milho. Pesquisa Agropecuária Brasileira, Brasília, v. 19, n. 1, p. 1-7, 1984.

CRUZ, C., TURPIN, F.T. Efeito da Spodoptera frugiperda em diferentes estádios de crescimento da cultura do milho. Pesquisa Agropecuária Brasileira, Brasília, v. 17, n. 3, p. 355-359, 1982.

CRUZ, I., RIVERA, J., VIANA, P.A. et al. Controle da lagartado-cartucho, Spodoptera frugiperda (Smith) em milho com diferentes inseticidas aplicados com dois volumes de água e impacto sobre o predador, Doru luteipes (Scudder). In: CONGRESSO NACIONAL DE MILHO E SORGO, 21, 1996. Londrina, PR. Resumos... Associação Brasileira de Milho e Sorgo - ABMS/IAPAR, 1996. p. 322.

MARTINS, J.C., SAWADA, E.M. Inseticidas químicos e fisiológicos no controle da lagarta do cartucho Spodoptera frugiperda (J.E. Smith) na cultura do milho. In: CONGRESSO BRASILEIRO DE ENTOMOLOGIA, 15, 1995. Caxambu, MG. Resumos... Sociedade Entomológica do Brasil/ESAL, 1995. p. 471.

SILVA, A.G.d A., GONÇALVES, C.R., GALVÃO, O.M. $\boldsymbol{e}$ t al. Quarto catálogo dos insetos que vivem nas plantas cultivadas do Brasil; seus parasitos e predadores. Rio de Janeiro: Ministério da Agricultura, 1968. v. 1, pt. 2, 622 p.

Ciência Rural, v. 29, n. 3, 1999. 